\title{
Study on Laser Micro-Cladding Integrated Circuit Manufacturing Equipment Control System
}

\author{
T. Wang* \\ Faculty of Mechanical Engineering \\ Hebei University of Technology \\ Tianjin \\ College of Mechanical and Electrical Engineering \\ Harbin Eng ineering University \\ Harbin \\ * Corresponding author
}

\author{
D.Z. Zhao, F.Z. Li \\ Faculty of Mechanical Eng ineering \\ Hebei University of Technology \\ Tianjin \\ Jin Tian Yang Laser Electronic Co \\ LTD, WuXi
}

\author{
Z. Wang \\ Jin Tian Yang Laser Electronic Co \\ LTD, WuXi \\ College of Mechanical and Electrical Engineering \\ Harbin Eng ineering University \\ Harbin
}

\begin{abstract}
Among the micro-cladding integrated circuit-based manufacturing equipment, we use closed-loop control of the laser output control unit to precisely control the laser power and change the power of the laser beam. Equipment adopt galvanometer control card and AT89S52. Method of communication using RS232 serial communication, using Time To Live (TTL) level to control the Q-switching through Computer numerical control (CNC) adjustable external control mode. Real-time acquisition of power of the laser beam and timely feedback, and then adjusting the laser power output current size, repeat feedback regulation, until the laser output power reaches the target accurately.
\end{abstract}

Keywords-micro-cladding; switching; closed-loop control

\section{INTRODUCTION}

In microprocessor-based cladding circuit manufacturing equipment used to make a variety of different components with different metal powder composition, its melting point is also different, so to strictly control the optical power of the laser beam, it is possible to make different kinds of metal powder to achieve the best cladding effect, precise control of the laser power to change the power of the laser beam is critical. Laser output control unit of the control system using closed-loop control, real-time acquisition of power of the laser beam and timely feedback, and then adjusting the laser power output current size, repeat feedback regulation, until the laser output power reaches the target accurately.

\section{AT89S52 AND MAX232 PRACTICAL SYSTEM DEVELOPMENT}

In this paper, a control circu it with a galvanometer control card, also using AT89S52, communication using RS232 serial communications.

\section{A. MCU Development}

We selected ATMEL company's AT89S52 microproces sor, which has the following advantages: low power, high performance, and support In-system programmable (ISP) advantages, AT89S52 is compatible with the MCS-51 microcontroller series [1].

\section{B. Microcontroller Circuit Interface}

According to the principle of overall control hardware circuit design, we can design a basic circuit AT89S52 microcontroller, shown in Figure 1, the design chosen communication interface standard interface, and consider matching the transmission medium, the level of conversion, a standard interface to easily put the microcontroller and peripherals, measuring instruments and other organically connected to form a control system.

In the communication section, there are three ways to choose: RS232, TTL serial and custom two-wire mode[2]; this article using RS232 serial communication, it is by using a serial interface chip MAX232 standard DB9 and PC directly connected to a network system while readers use it to debug the system, eliminating the need for multiple single-chip design stage production card reader hardware system, so the PC can not only manage the online readers, but also for the general manage ment of machine, card reader and $\mathrm{PC}$ relatively independent of each machine, PC function better handle other administrative matters. Maxim's MAX232 is dedicated serial interface chip, which includes two-way receiver and drive, take this article transceiver chip which has a power supply voltage converter to $+5 \mathrm{~V}$ power input voltage is converted to RS232 output levels $\pm 10 \mathrm{~V}$ required voltage (negative logic), therefore, the system uses this chip serial communication interface is just a single $+5 \mathrm{~V}$ supply.

(1) RS232 communication interface chip features 
Single $5 \mathrm{~V}$ power supply and other readers in the same chip operating voltage;

Meet all EIA / TIA-232E standard;

Multiple input and output.

(2) RS232 Standard Message Format

RS232 using serial format, shown in Figure 1, this standard specifies: start information is the start bit, stop bit of information is ended; information itself can be 5,6,7,8 bits, plus one parity bit [3]. If there is no information between the two information, write " 1 " to indicate empty.

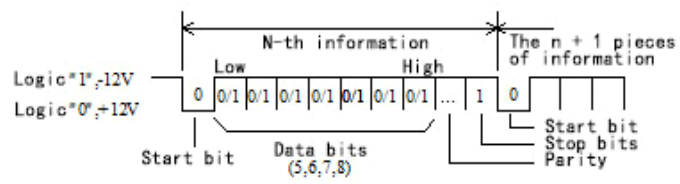

FIGURE I. .RS232 INFORMATION FORMAT.

(3) RS232 level converter

RS232 provides its own electrical standards, as it is developed before the TTL circuits, so it is not the level of + $5 \mathrm{~V}$ and ground, instead of using negative logic: the logic " 0 ": $+3 \mathrm{~V} \sim+15 \mathrm{~V} ; \operatorname{logic} " 1 ":-3 \mathrm{~V} \sim-15 \mathrm{~V}$.

Therefore, RS232 and TTL level can not be directly connected. Must be level conversion when used, or will burn TTL circuits, we must note that in the practical application, common level converter IC is a transmission line driver MC1488 and the trans mission line receiver MC1489, used in this design is another common level conversion circuit is MAX232.

\section{THE ELECT RICAL CONNECTION OF LASER MICRO- CLADDING SCANNING GALVANOMETER SYSTEM}

Laser micro-cladding scanning galvanometer system wiring connection diagram shown in Figure 2.

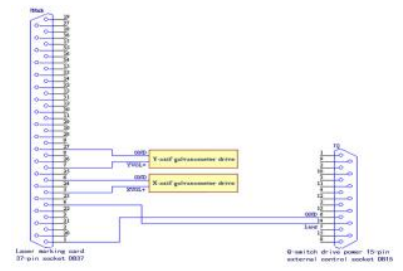

FIGURE II. GALVANOMETER SCANNING SYSTEM CIRCUIT CONNECTION GRAPH.

Laser marking card's 4th pin and first pin output light control signal[4], 4th pin output high level and low level, first pin is GND, the output is TTL level. Q-switch drive power's 14th pin and 6th pin receive light control signal, and then complete the truncated laser and laser appeared, 14th pin high and low input, 6-pin connector and GND, TTL level input, Q switch drive power can be set high or low for effective optical signal. 14th pin input high level and low level, 6th pin is connected to GND, TTL level input, Q switch driver power supply can be set high or low for effective optical signal.
Laser marking card's 5th pin and 6th pin output galvanometer $\mathrm{X}$ axis servo motor drive signal, 7th pin and 27 th pin output galvanometer $\mathrm{Y}$ axis servo motor drive signals. Galvano meter servo motor using a 28V DC power supply.

\section{LASER POWER SUPPLY CURRENT REGULATING CIRCUIT}

Laser power operating mode is divided into two kinds: internal control mode and external control mode. Under the internal model, only by manual adjustment of the laser power supply current. Laser power supply with external control interface for 25-p in female socket, the model is DB25/ F, we can connect the external control circuit via a standard 25-pin pin connector, shown in Figure 3, the external control interface as defined in Table 1 show.

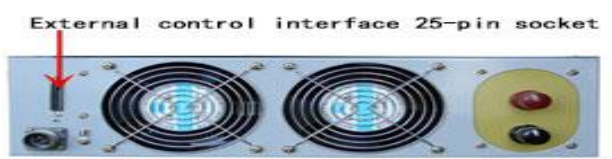

FIGURE III. BACK OF LASER POWER.

The * Ie of Table 1 represents the rated current, external control mode machine control signal input requirements for standard TTL level, when input some other level of the enter signal, the current flowing through the op to coupler diode to be met:

(1) When the circuit is turned on, the current is greater than $5 \mathrm{~mA}$ and less than $10 \mathrm{~mA}$;

(2) When the circuit is turned off, the current is less than $0.1 \mathrm{~mA}$.

Under external control mode, there are two ways to adjust the operating current, analog voltage regulator and TTL level adjustment. We use current analog voltage regulator work in two ways:

(1) potentiometer adjustment. Select the external control of the work. Adjust the

potentiometer, the operating current of the machine will be between sleep

current and maximum allowable operating current continuous change

(potentiometer resistance take $1 \mathrm{~K} \Omega$ ).

(2) Analog voltage signal provided directly to the set voltage. Between the 13th

feet (positive terminal) and 25th feet (negative side) with a forward voltage

signal, you can set the operating current of the machine:

Setting the operating current $(\mathrm{A})=$ Rated current $(\mathrm{A}) / 9.0$ (V) $\times$ external

setting voltage signal(V)

For 30A Laser Power:

Setting the operating current $(A)=(30.0 / 9.0) \times$ external setting voltage 
signal (V)

For 20A Laser Power:

Setting the operating current $(A)=(20.0 / 9.0) \times$ external setting voltage

signal (V)

Analog voltage regulator operating current data flow shown in Figure 4.

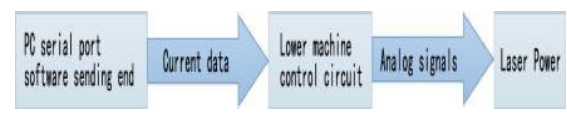

FIGURE IV. SIGNAL AND DATA ST REAM IN DIGIT AL COMMUNICATIONS.

TABLE I .DEFINITION OF 25 PINS.

\begin{tabular}{|c|c|c|c|}
\hline Pin & Code & Name & Definitions \\
\hline $\begin{array}{l}13 \\
25\end{array}$ & $\begin{array}{l}\text { VIN+ } \\
\text { VIN- }\end{array}$ & \begin{tabular}{ll|}
$\begin{array}{l}\text { Analog } \\
\text { voltage+ }\end{array}$ & input \\
Analog & input \\
voltage- &
\end{tabular} & $\begin{array}{l}\text { External control current is set analog } \\
\text { input signal. When the external control } \\
\text { state, 13th, 25th feet enter } 0-9.0 \mathrm{~V} \text {, } \\
\text { corresponding } 0 \text {-Ie current. }\end{array}$ \\
\hline $\begin{array}{l}12 \\
24\end{array}$ & $\begin{array}{l}\mathrm{VC}+ \\
\mathrm{VC}-\end{array}$ & $\begin{array}{l}\text { High reference } \\
\text { voltage } \\
\text { Low reference } \\
\text { voltage }\end{array}$ & $\begin{array}{l}\text { High and low reference voltage analog } \\
\text { output signal. }\end{array}$ \\
\hline $\begin{array}{l}11 \\
23\end{array}$ & $\begin{array}{l}\text { VOUT + } \\
\text { VOUT- }\end{array}$ & $\begin{array}{l}\text { Analog output } \\
\text { voltage+ } \\
\text { Analog output } \\
\text { voltage- }\end{array}$ & $\begin{array}{l}\text { SELECT button on the operation pane } \\
\text { can select the output current, voltage or } \\
\text { power signal. When an external high- } \\
\text { impedance load, the output voltage of } \\
6.0 \mathrm{~V} \text { corresponding to the current of } 40 \mathrm{~A} \\
\text { (display current) or voltage of } 400 \mathrm{~V} \\
\text { (display voltage). }\end{array}$ \\
\hline $\begin{array}{l}10 \\
22\end{array}$ & $\begin{array}{l}\text { VCC-O } \\
\text { GND }\end{array}$ & $\begin{array}{l}\text { Internal voltage } \\
\text { VCC } \\
\text { Internal ground } \\
\text { GND }\end{array}$ & $\begin{array}{l}\text { 10th and } 22 \text { th pin provide a set of } \mathrm{VCC}(+ \\
5 \mathrm{~V}) \mathrm{DC} \text { power supply for external analog } \\
\text { input and output signals, the output } \\
\text { current requirement is }<200 \mathrm{~mA} \text {. }\end{array}$ \\
\hline $\begin{array}{c}9 \\
18\end{array}$ & $\begin{array}{l}+5 \mathrm{~V}-\mathrm{O} \\
\mathrm{COM}-\mathrm{O}\end{array}$ & $\begin{array}{l}\text { External } \\
\text { voltage }+5 \mathrm{~V} \\
\text { external } \\
\text { voltage } 0 \mathrm{~V}\end{array}$ & $\begin{array}{l}9 \text { th and } 18 \text { th pin provide a set of }+5 \mathrm{VDC} \\
\text { power supply for external digital input } \\
\text { and output signals, the output current } \\
\text { requirement is }<200 \mathrm{~mA} \text {. }\end{array}$ \\
\hline 21 & DHCG & $\begin{array}{l}\text { Light triggen } \\
\text { success }\end{array}$ & $\begin{array}{l}\text { TTL level signal output high level after } \\
\text { the success of light trigger. }\end{array}$ \\
\hline 8 & $\begin{array}{l}\text { ALAR } \\
\text { M }\end{array}$ & Alert & $\begin{array}{l}\text { TTL level signal output low when the } \\
\text { machine fails. }\end{array}$ \\
\hline 20 & POWER & Power Good & $\begin{array}{l}\text { TTL level signal output low level when } \\
\text { the control power supply is normal. }\end{array}$ \\
\hline 7 & READY & Ready & $\begin{array}{l}\text { TTL level signal output low level when } \\
\text { the power is normal. }\end{array}$ \\
\hline 19 & STOP & Stop state & $\begin{array}{l}\text { TTL level signal output low level when at } \\
\text { a standstill. }\end{array}$ \\
\hline 6 & RUN & Operating status & $\begin{array}{l}\text { TTL level signal output low level when in } \\
\text { operation. }\end{array}$ \\
\hline 5 & $\mathrm{XM}$ & Sleep request & $\begin{array}{l}\text { TTL level input signal sleep at a low level } \\
\text { and work in a high level. }\end{array}$ \\
\hline 17 & QD & Start & $\begin{array}{l}\text { TTL level input signal is effective at a } \\
\text { low level. }\end{array}$ \\
\hline 4 & TZ & Stop & $\begin{array}{l}\text { TTL level input signal is effective at a } \\
\text { high level. }\end{array}$ \\
\hline $\begin{array}{c}16 \\
3\end{array}$ & $\begin{array}{l}\text { WK } \\
\text { COM }\end{array}$ & $\begin{array}{l}\text { External control } \\
\text { stops } \\
\text { External shared }\end{array}$ & $\begin{array}{l}\text { Shorting between 16th and 3th pin, } \\
\text { meaning start allowed. otherwise, the } \\
\text { meaning is to start the ban. }\end{array}$ \\
\hline 15 & QR & Confirm & Effective at a low level. \\
\hline $\begin{array}{c}2 \\
14\end{array}$ & $\begin{array}{l}\text { DAT A+ } \\
\text { DAT A- }\end{array}$ & $\begin{array}{l}\text { Data+ } \\
\text { Data- }\end{array}$ & $\begin{array}{l}\text { Effective at a low level. } \\
\text { Effective at a low level. }\end{array}$ \\
\hline 1 & RESET & Reset & Reservations, undefined \\
\hline
\end{tabular}

The control system uses TTL level digital adjustment of external control mode[4], Numerical Control (NC) directly send the current data to the laser power, laser power settings to internal digital circuitry for processing. We can capture the current feedback signal after the laser power setting internal circuit current, this approach can accurately set the output current size, although there is a delay in the time, but its delay length within the allowable range, so the use of numerical methods TTL level is the best choice. Test found, PC parallel port output level to meet TTL level requirements, so this control system uses a PC parallel port to control the laser power [5], PC parallel port and the 25th pin of laser power circuit connection diagram shown in Figure 5.

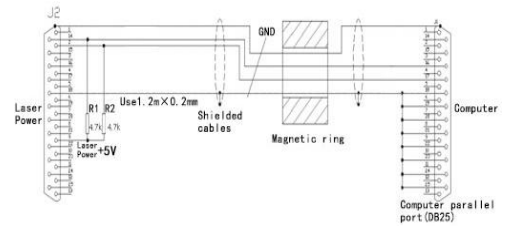

FIGURE V. PARALLEL PORT OFPC AND 25 PINS OF LASER POWER CONNECTION GRAPH.

As can be seen from Figure 5, PC parallel port is not a simple connection the 25 th pin of laser power to complete the data transfer, laser power clock signal line and the laser power data signal lines are connected to the pull-up resistor $4.7 \mathrm{~K} \Omega$, laser power supply $+5 \mathrm{~V}$ output pin is connected to the other end of the pull-up resistor. Prior to the pull-up resistor is not connected with the oscilloscope measured waveform display, PC parallel port drive capability is not enough for the laser power supply external control interface, therefore, the two cables were added pull up resistor. Outside the "cable" setting up a magnetic ring and a shield, In order to prevent highfrequency data transmission or external electromagnetic interference fleeing, effectively ensuring the reliability of data transmis sion.

The control system uses external control mode TTL-level digital adjustment, the circuit is simple, and there is a great advantage on cost, the focus of this control method in the programming software.

\section{CONCLUSION}

In this paper, we have successfully achieved the closedloop control of the laser output control unit and real-time acquisition of the laser beam power and timely feedback. By adjusting the laser power output current size, coupled with feedback regulation, we can achieve a laser output power accuracy within $\pm 10 \mathrm{~mW}$ and different types of cladding metal powder to achieve the best results.

\section{REFERENCES}

[1] Li Chaoqing. PC, and SCM data communications technology. Beijing: Beihang University Press, 2000.

[2] A.L. Rasumussen. Transfer Standards for Energy and Peak Power of Low-level, 1.064 micrometer Laser Pulses and Continues Wave Laser Power. Optical Engineering, 10(250), pp. 227-285,1982.

[3] Chen Zhangwei, Li Yuhe, Li Qingxiang. Photodetector preamp circuit design and research. Electrical Measurement \& Instrumentation. 42(6), pp. 32-34, 2005. 
[4] Shi Xiufang, Jiang Taihui. 8031 Data Acquisition System. Computer Applications. 27(42), pp. 2-4, 1992.

[5] W.H. James. High Accuracy Laser Power Meter.SPIE. 20(22), pp. 165173, 1993. 